\title{
NOTE
}

\section{Antarctic krill Thysanoessa macrura fills a major gap in marine lipogenic pathways}

\author{
Gerhard Kattner $^{1,}$, Wilhelm Hagen ${ }^{2}$, Stig Falk-Petersen ${ }^{3}$, John R. Sargent ${ }^{4}$, R. James Henderson ${ }^{4}$ \\ ${ }^{1}$ Alfred-Wegener-Institut für Polar- und Meeresforschung, Sektion Chemie, Postiach 120161, D-27515 Bremerhaven, Germany \\ ${ }^{2}$ Institut für Polarökologie, Universität Kiel, Wischhofstraße 1-3, Gebäude 12, D-24148 Kiel, Germany \\ ${ }^{3}$ Norsk Polarinstitutt, PO Box 399, N-9001 Tromse, Norway \\ ${ }^{4}$ NERC Unit of Aquatic Biochemistry, Department of Biological and Molecular Sciences, University of Stirling, Stirling FK9 4LA, \\ United Kingdom
}

\begin{abstract}
The unique predominance of oleyl alcohols $(18: 1)$ is the striking characteristic of the lipids of the Antarctic euphausiid Thysanoessa macrura. The 2 isomers $18: 1(\mathrm{n}-9)$ and $18: 1(n-7)$ occurred in similar proportions in the wax esters of T. macrura and comprised up to $80 \%$ of the total fatty alcohols. The remainder consisted mostly of the 20:1(n-9) alcohol along with small amounts of the 22:1(n-11) alcohol. No marine zooplankton species has previously been reported which produces wax esters with significant amounts of 18 carbon fatty alcohols. T. macrura specimens were collected in the high Antarctic Weddell Sea during autumn 1992 and summer 1993. Their lipid levels were high, about 40 to $50 \%$ of the dry mass with up to $70 \%$ of the total lipid as wax esters. The wax ester fatty acids were dominated by the saturates 14:0 and 16:0, which, along with the monounsaturate $18: 1(n-9)$, accounted for more than $80 \%$ of the total fatty acids. Phospholipids contained high levels of $(n-3)$ polyunsaturated fatty acids (20:5 and 22:6) typical of membrane lipids from marine zooplankton. The precise significance of the unique wax ester composition in $T$. macrura is not clear but this discovery underscores the biochemical adaptability of Antarctic zooplankton species to a constantly cold and highly seasonal polar environment
\end{abstract}

KEY WORDS: Euphausiids - Lipid biosynthesis - Fatty acids and alcohols Wax esters Weddell Sea

Lipids play a key role as energy reserves in marine organisms from high latitudes. Polar zooplankton species in particular are well known for their efficient pathways of lipid biosynthesis which produce mainly wax esters (e.g. Lee \& Hirota 1973, Clarke 1983, Sargent \& Falk-Petersen 1981, Kattner et al. 1989, 1994, Conover \& Huntley 1991, Kattner \& Hagen 1995). In the plant and animal kingdoms in general, wax esters are a relatively rare form of storage lipid. The basic

•E-mail: gkattner@awi-bremerhaven.de enzyme underlying the de novo formation of wax esters (and also triacylglycerols) is the Type-I fatty acid synthetase, which is present in all animals studied so far, including marine zooplankton (Sargent \& Henderson 1986). The chain-length specificity of the processes forming wax esters in marine zooplankton varies substantially such that different species produce different wax esters of quite different fatty acid and fatty alcohol compositions. Characteristic of many carnivorous and omnivorous zooplankton species is the synthesis of shorter-chain alcohols (14:0 and 16:0) as wax ester moieties, whereas the wax esters of herbivorous species, especially the large calanoid copepods, consist mainly of long-chain alcohols (20:1 and 22:1). Surprisingly, none of the species examined so far contain large amounts of fatty alcohols with 18 carbon atoms, despite the corresponding fatty acid $18: 1(n-9)$ being a major component of the lipids of many zooplankton species, including their wax esters (Lee et al. 1971, Graeve et al. 1994, Hagen et al. 1995).

The Antarctic krill species are known for their diverse modes of lipid storage. Euphausia superba deposits primarily triacylglycerols, whereas Euphausia crystallorophias and Thysanoessa macrura accumulate wax esters (Hagen 1988). The lipid composition of the Euphausia species has been studied (e.g. Bottino 1974 , 1975, Clarke 1980, Fricke et al. 1984, Virtue et al. 1993), but nothing is known about the fatty acid and alcohol compositions of $T$. macrura. To rectify this deficiency, we analysed the lipids of $T$. macrura in detail. The investigations were aimed at a better understanding of lipid biosynthetic pathways in dominant Antarctic krill species so as to help elucidate biochemical adaptations to the extreme Antarctic environment. 
Methods. Adult specimens of Thysanoessa macrura were sampled in the eastern. Weddell Sea near the continental slope during the Antarctic expeditions of the RV 'Polarstern' (ANT X/3) in April/May 1992 and of the RV 'Polarbjørn' (NARE 92/93) in January 1993. Specimens for lipid analyses were carefully sampled by different nets from the upper $500 \mathrm{~m}$. For each lipid sample single specimens were sorted according to size and sex, and immediately frozen in glass vials at $-80^{\circ} \mathrm{C}$.

The samples from the 'Polarstern' cruise were lyophilised for $48 \mathrm{~h}$ to determine dry mass and then extracted with dichloromethane:methanol (2:1 by vol.). The samples from the 'Polarbjørn' cruise were extracted frozen with chloroform:methanol (2:1 by vol.). Both extractions essentially followed the method of Folch et al. (1957). The total lipid content of the 'Polarstern' samples was measured gravimetrically and expressed as percentage of dry mass. The lipid class composition of the 'Polarbjørn' samples was measured by quantitative thin-layer chromatography/densitometry as described by Olsen \& Henderson (1989). Wax esters and phospholipids were isolated by thin-layer chromatography on silicic acid.

For yas-liquid chromatographic analyses of the 'Polarstern' samples, methyl esters of fatty acids and free fatty alcohols were prepared from the total lipid and purified wax esters and phospholipids by transesterification with $3 \%$ concentrated sulphuric acid in methanol for 4 h at $80^{\circ} \mathrm{C}$. After extraction with hexane, fatty acid methyl esters and free fatty alcohols were analysed simultaneously in a single run with a Carlo Erba gas-liquid chromatograph (HRGC 5300) on a $30 \mathrm{~m}$ capillary column (film thickness: $0.25 \mu \mathrm{m}$; liquid phase: DB-FFAP) (Kattner \& Fricke 1986) and were identified using standard mixtures. The identity of the 18:1 alcohols was verified by combined gas-liquid chromatography/mass spectrometry.

For the 'Polarbjørn' samples, wax esters were saponified using potassium tertiary-butoxide and the resulting free fatty acids and free fatty alcohols isolated by thinlayer chromatography. Fatty alcohols were converted to acetate esters by reaction with acetic anhydride in pyridine (Farquhar 1962). Fatty acids were converted to methyl esters by transmethylation in methanol containing $2 \%$ sulphuric acid for 16 h at $50^{\circ} \mathrm{C}$. Fatty acid methyl esters and fatty alcohol acetates were analysed by gas-liquid chromatography essentially as above and as detailed by Henderson et al. (1995).

Results and discussion. In comparison to other polar zooplankton, adult Thysanoessa macrura exhibit a high lipid content by the end of the productive season, usually between 40 and $50 \%$ of its dry mass, which is characteristic of herbivorous copepods. However, the wax ester deposits of up to $70 \%$ in $T$ macrura do not reach the extremely high levels (up to $90 \%$ of the total lipid) commonly reported for the very lipid-rich herbivorous copepods (Lee 1974, Hagen 1988, Kattner et al. 1989, 1994, Kattner \& Hagen 1995)

The fatty acid compositional data of Thysanoessa macrura were similar in both sexes and seasons and fall within the range already established for other polar zooplankton species, including the occurrence of the $18: 1(n-9)$ and $18: 1(n-7)$ fatty acids. The wax esters of $T$. macrura were dominated by the saturated fatty acids 14:0 and 16:0, which, along with the monounsaturated fatty acids $18: 1(n-9), 18: 1(n-7)$ and $16: 1(n-7)$, accounted for 80 to $90 \%$ of the total acids. The polyunsaturated fatty acids $20: 5(n-3)$ and $22: 6(n-3)$ were scarce in the wax esters but, as typical membrane fatty acids, they constituted almost $50 \%$ of the total fatty acids in the polar lipids which were mainly phospholipids (Table 1 ).

In contrast, the fatty alcohol composition of Thysanoessa macrura is strikingly different from any other zooplankton species due to its high levels of $18: 1(n-9)$ and $18: 1(n-7)$ alcohols. This was established independently in 2 different laboratories using partially different methods. The 2 isomers of oleyl alcohol, 18:1(n-9) and 18:1(n-7), accounted respectively for $35 \%$ and $31 \%$ of total fatty alcohols in females and $41 \%$ and $38 \%$ in males. In addition, the $20: 1(n-9)$ alcohol accounted for $26 \%$ of the alcohols in females and $18 \%$ in males. The corresponding fatty acids occurred only in low percentages, except for 18:1(n-9), which accounted for $12 \%$ of the total fatty acids (Table 1 ).

Fatty alcohols are biosynthesised from their corresponding fatty acids by a fatty acyl coenzyme A reductase (Sargent \& Hendersen 1986). Therefore, the abundance of $18: 1(n-9)$ and $18: 1(n-7)$ fatty alcohols in Thysanoessa macrura requires abundant sources of 18:1(n-9) and 18:1(n-7) fatty acid substrates to be present in the animal. There are 3 possible sources for such substrates, the first being de novo biosynthesis in the animal by the Type-I fatty acid synthetase, in which case the 18:0 and 16:0 end products of the synthetase must be converted by the $\Delta-9$ fatty acid desaturase to 18:1(n-9) and 16:1(n-7), respectively, with 16:1(n-7) subsequently being chain-elongated to $18: 1(\mathrm{n}-7)$. Second, 18:1(n-9) and 18:1(n-7) could be formed by the elongation and, if necessary, the $\Delta-9$ desaturation of a range of shorter-chain saturated and monounsaturated fatty acids, particularly 14:0,16:0 and 16:1(n-7), derived solely from the krill's diet. It is known that the 16:1(n-7) fatty acid, the obvious precursor of the 18:1(n-7) alcohol in T. macrura, is abundant in diatom lipid (e.g. Kates \& Volcani 1966, Ackman et al, 1968). The omnivorous T. macrura could ingest $16: 1(n-7)$ fatty acid directly with phytoplankton, or indirectly by predation on herbivores. However, a substantial supply of $16: 1(n-7)$ fatty acid would be necessary to yield the large amounts of final 18:1(n-7) alcohol. The 18:1(n-9) fatty acid, the pre- 
Table 1 Thysanoessa macrura. Average composition of major fatty acids and alcohols of total lipid and lipid classes (weight \%). Females (F) and males (M) from the Weddell Sea. Means and standard deviations (SD) are from 4 samples each

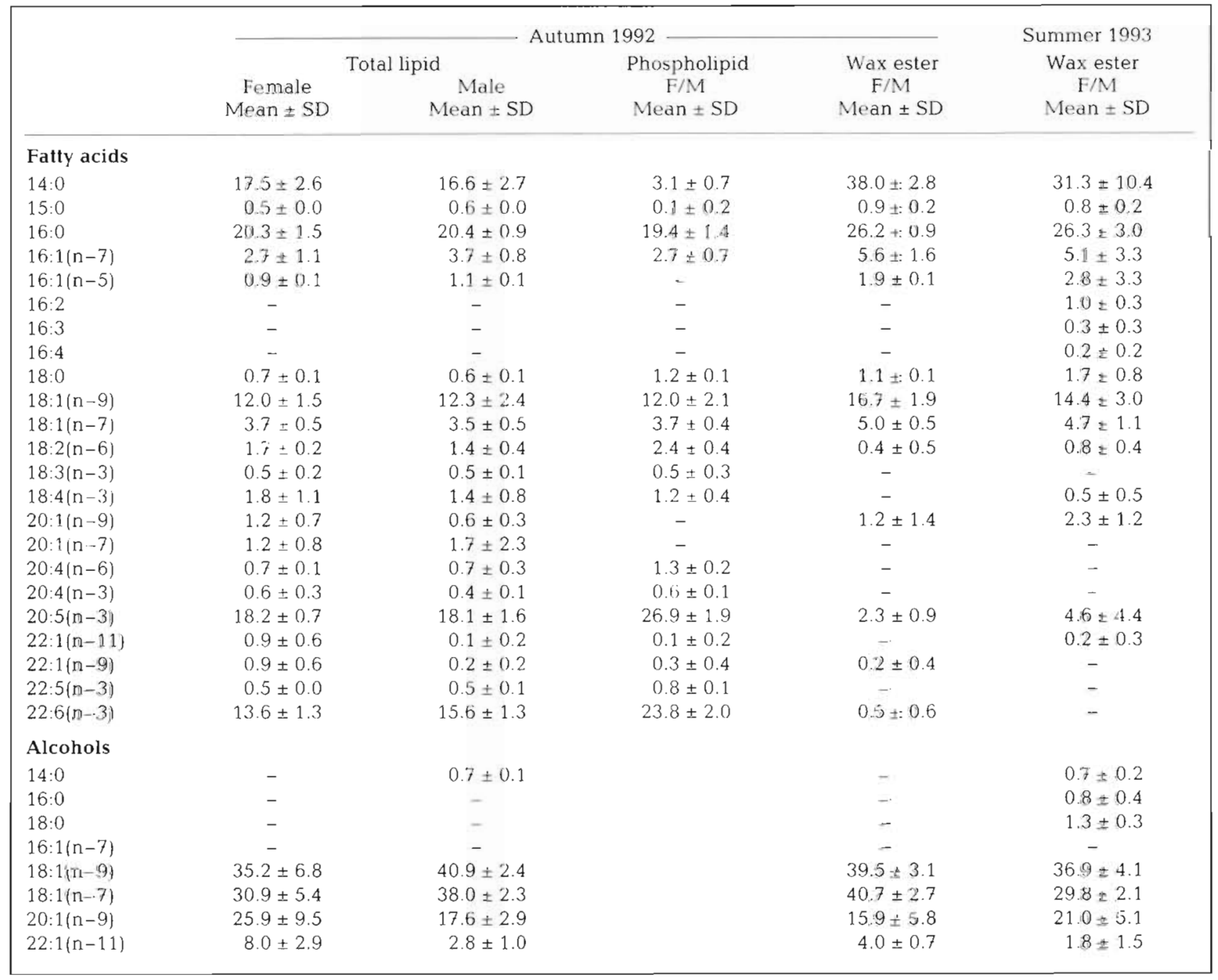

cursor of the 18:1(n-9) alcohol, has been used as an indicator for carnivorous and omnivorous feeding on the grounds that $18: 1(\mathrm{n}-9)$ is readily biosynthesised de novo by many animals (e.g. Falk-Petersen et al. 1990). Third, the 18:1(n-9) and 18:1(n-7) fatty acids in $T$. macrura could be derived entirely from its diet, an unlikely possibility. The presence of substantial amounts of the 20:1(n-9) fatty alcohol in T. macrura also points to active fatty acid chain elongation in the animal. The required pathways of biosynthesis of the fatty alcohols in $T$. macrura are summarised in Fig. 1

The biosynthesis of predominantly C18 fatty alcohols does not occur in the other dominant Antarctic and Arctic krill species. The Antarctic Euphausia crystallorophias and the Arctic Thysanoessa inermis also primarily deposit wax esters but their fatty alcohol compositions are notably different because they synthesise only shorter-chain fatty alcohols, 14:0 and 16:0 (Bottino

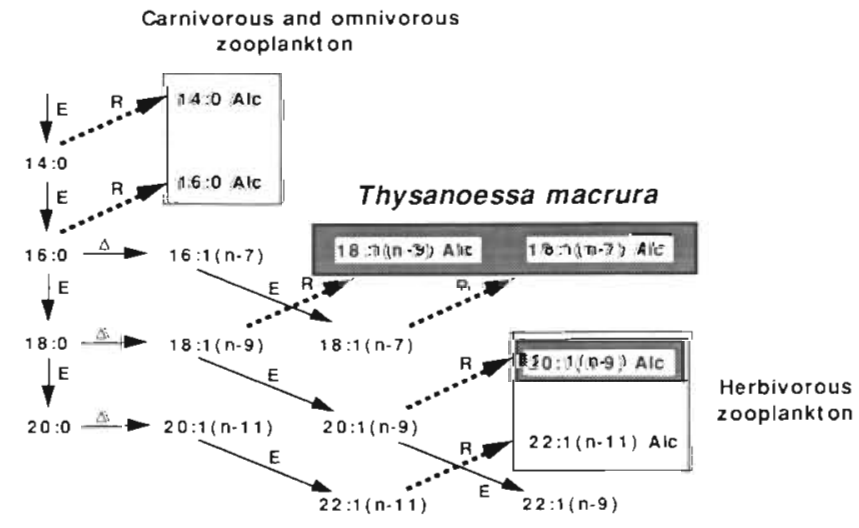

Fig. 1. Thysanoessa macrura. Blosynthetic pathway of lipids in polar zooplankton with special regard to the dominant alcohols (in shaded boxes) in T. macrura. E: elongation; $\Delta$ : desaturation by $\Delta-9$ desaturase; $R$ : fatty acid reduction to alcohol (Alc) 
1975, Sargent \& Falk-Petersen 1981, present study data not shown). It is noteworthy that the longer-chain alcohols in Thysanoessa macrura yield higher calorific contents than the shorter-chain alcohols of E. crystallorophias and $T$. inermis. However, this is countered in $T$ macrura by predominantly shorter-chain, mainly 14:0 and 16:0, fatty acids, which yield lower calorific contents than the dominant 18:1 fatty acid in the 2 other euphausiids. Hence, the specific calorific values of the wax esters in all 3 krill species will be essentially similar.

In summary, this investigation has established that $18: 1(n-9)$ and $18: 1(n-7)$ fatty alcohols dominate the wax esters of Thysanoessa macrura. This is the first zooplankton species known to biosynthesise large amounts of fatty alcohols of chain lengths intermediate between those of other polar euphausiids and the large herbivorous calanoid copepods. Thus, $T$. macrura has developed a lipogenic pathway which completes the possible options for the biosynthesis of fatty alcohols and hence wax esters. The existence of such a wide spectrum of lipid biosynthetic pathways, especially in Antarctic zooplankton, emphasises the biochemical adaptability of these species under constantly cold and highly seasonal environmental conditions. This biochemical 'diversity' may also reflect the intense and long-lasting evolutionary processes in this very old high latitude ecosystem.

Acknowledgements. We appreciate the skilful support of A. Terbrüggen and R.-M. Millar and are grateful to $K$. Weber and W. Drebing for the GC-MS analyses. We thank captains and crews of the RV 'Polarstern' and the RV 'Polarbjorn' for their professional assistance. The study was partially supported by the 'Deutsche Forschungsgemeinschaft'. This is contribution no. 1018 of the Alfred Wegener Institute for Polar and Marine Research.

\section{LITERATURE CITED}

Ackman RG, Tocher CS, McLachlan J (1968) Marine phytoplankter fatty acids. J Fish Res Bd Can 25:1603-1620

Bottino NR (1974) The fatty acids of Antarctic phytoplankton and euphausiids. Fatty acid exchange among trophic levels of the Ross Sea. Mar Biol. 27:197-204

Bottino NR (1975) Lipid composition of two species of Antarctic krill: Euphausia superba and E. crystallorophias. Comp Biochem Physiol 50B:479-484

Clarke A (1980) The biochemical composition of krill, Euphausia superba Dana, from South Georgia. J Exp Mar Biol Ecol 43:221-236

Clarke A (1983) Life in cold water the physiological ecology of polar marine ectotherms. Oceanogr Mar Biol A Rev 21 $341-453$

Conover RJ, Huntley ME (1991) Copepods in ice-covered seas - distribution, adaptations to seasonally limited food, metabolism, growth patterns and life cycle strategies in polar seas. J Mar Syst 2:1-40

Falk-Petersen S, Hopkins CCE, Sargent JR (1990) Trophic relationships in the pelagic arctic food web. In: Barnes M. Gibson RN (eds) Trophic relationships in the marine environment. Proc 24th Eur Mar Biol Symp. Aberdeen
University Press, Aberdeen, p 315-333

Farquhar JW (1962) Identification and gas-liquid chromatographic behaviour of plasmalogen aldehydes and their acetal, alcohol and acetylated alcohol derivatives. J Lipid Res 3:21-30

Folch J, Lees M, Sloane-Stanley GH (1957) A simple method for the isolation and purification of total lipides from animal tissues. J Biol Chem 226:497-509

Fricke $H_{1}$ Gercken G, Schreiber W, Oehlenschläger J (1984) Lipıd, sterol and fatty acid composition of Antarctic krill (Euphausia superba Dana). Lipids 19:821-827

Graeve M, Hagen W, Kattner G (1994) Herbivorous or omnivorous? On the significance of lipid compositions as trophic markers in Antarctic copepods. Deep Sea Res 41:915-924

Hagen W (1988) Zur Bedeutung der Lipide im antarktischen Zooplankton. Ber Polarforsch 49:1-129 (in German) (English version (1989): On the significance of lipids in Antarctic zooplankton. Can Trans Fish Aquat Sci 5458:1-149]

Hagen W, Kattner G, Graeve M (1995) On the lipid biochemistry of polar copepods: compositional differences in the Antarctic calanoids Euchaeta antarctica and Euchirella rostromagna. Mar Biol 123:451-457

Henderson RJ, Park MT, Sargent JR (1995) The desaturation and elongation of ${ }^{14} \mathrm{C}$-labelled polyunsaturated fatty acids by pike (Esox lucius L.) in vivo. Fish Physiol Biochem 14 $223-235$

Kates K, Volcanı BE (1966) Lipid components of dıatoms Biochim Biophys Acta 116:264-278

Kattner G. Fricke HSG (1986) Simple gas-liquid chromatographic method for the simultaneous determination of fatty acids and alcohols in wax esters of marine organisms. J Chromat 361:263-268

Kattner G, Graeve M, Hagen W (1994) Ontogenetic and seasonal changes in lipid and fatty acid/alcohol compositions of the dominant Antarctic copepods Calanus propinquus, Calanoides acutus and Rhincalanus gigas. Mar Biol 118: $637-644$

Kattner G, Hagen W (1995) Polar herbivorous copepods different pathways in lipid biosynthesis. ICES J Mar Sci 52:329-335

Kattner G, Hirche HJ, Krause M (1989) Spatial variability in lipid composition of calanoid copepods from Fram Stralt, the Arctic. Mar Biol 102:473-480

Lee RF (1974) Lipid composition of the copepod Calanus hyperboreus from the Arctic ocean. Changes with depth and season. Mar Biol 26:313-318

Lee RF, Hirota J (1973) Wax esters in tropical zooplankton and nekton and the geographical distribution of wax esters in marine copepods. Limnol Oceanogr 18:227-239

Lee RF, Hirota J, Barnett AM (1971) Distribution and importance of wax esters in marine copepods and other zooplankton. Deep Sea Res 18:11.47-1165

Olsen RE, Henderson RJ (1989) The rapid analysis of neutral and polar marine lipids using double development HPTLC and scanning densitometry. J Exp Mar Biol Ecol 129:189-197

Sargent JR, Falk-Petersen S (1981) Ecological investigations on the zooplankton community of Balsfjorden, northern Norway: lipids and fatty acids in Meganyctiphanes norvegica, Thysanoessa raschi and $T$ inermis during midwinter Mar Biol 62:131-137

Sargent JR, Henderson RJ (1986) Lipids. In: Corner EDS, O'Hara S (eds) Biological chemistry of marine copepods. Univ Press, Oxford, p 59-108

Virtue P, Nicol S, Nichols PD (1993) Changes in the digestive gland of Euphausia superba during short-term starvation: lipid class, fatty acid and sterol content and composition. Mar Biol 117:441-448 